\title{
The Correlation analysis of COVID-19 result and Stock Market : Study of BSE-Sensex
}

\author{
Dr. Viplaw Kishore Pandey
}

Former Registrar and Professor

Apeejay Stya University

Article History: Received: 10 November 2020; Revised 12 January 2021 Accepted: 27 January 2021; Published online: 5 April 2021

\begin{abstract}
It has been observed that from the month of Nov, 2020 BSE Sensex is back in its mood and is going has made an all time high. Now the market is in a jubilant mood. During the COVID-19 period the market has behaved like a roller costa and every good and bad news about the Pandemic has equivalently affected the Sensex too, if not in absolute terms at least in terms of its direction. The initial days of the Covid-19 pandemic has created a huge losses to the investors in the financial market. Almost all the economic activity was stopped which has resulted in a huge loss to the business. After the removal of the lockdown in phased wise manner the market particularly the stock market has a frequent swing and in last couple of month it has been able to reach all time high mark of $50 \mathrm{~K}$. The present article aims to analyse the journey of the BSE Sensex during the COVID-19 period from January second week of 2020 till date
\end{abstract}

Keywords:

\section{Introduction}

COVID -19 outbreaks has paralyzed all human activity of the entire globe and the financial market has not been any exception to this. The disruptions in the global market as well Indian stock market was obvious. The market has witnessed lot of volatility in the initial days of the Pandemic. On March, $23^{\text {rd }}$ the BSE Sensex had made a low of 25981 from an average range of 40000 mark of the pre Covid-19 period. It remained in the range of $25 \mathrm{k}$ to $30 \mathrm{k}$ till April, 20, in May, 20 it was in between $30 \mathrm{~K}$ to $32 \mathrm{~K}$ and reached back to its initial mark of $40 \mathrm{~K}$ in the month of October,20. This was the time when the majority of the restrictions of lockdown were relaxed in phased manner. The effect of pandemic was measured in terms of number of confirmed cases, number of active cases, number of recovered cases and number of deaths. The media has also given a high coverage to the news about this effect on daily basis. The research study tries to understand the correlation between these results and stock market indices i.e. SENSEX and NIFTY. Further the study tries to understand how these indices have behaved and had been able to absorb the information relating to these results on daily basis.

\section{Literature Review:}

Although not much published research was found on the topic of of COVID-19 pandemic impact on the financial market in India, however few related literature was available. Baret et al., (2020), in their research on financial markets and banks, have found that Covid-19 has impacted the fall in the price of the oil, equity, bonds throughout the world. UK's leading index FTSE has fallen more than 10\% on 12th March 2020 (Zhang, 2020). Georgieva (2020) pointed out that the COVID-19 pandemic brought the entire globe near to financial crises more hazardous than Global Crises 2007-08. Vishnoi and Mookerjee (2020) observed that the stock market in Japan had dropped more than $20 \%$ in December 2019. Shehzad (2020), in his study, also found a harm full impact on stock returns of the S\&P 500 and an inconsequential impact on the Nasdaq Composite index. Further As people have compressed their consumption only to necessary products only the FMCG Company has shown a positive return whereas other companies face a sharp decline (Rakshit and Basistha, 2020)

\section{Research Methodology:}

For the purpose of research secondary data was collected regarding the confirmed cased of COVID-19, active cases, recovered cases and the death cases during the period from $12^{\text {th }}$ March, 2020, and $13^{\text {th }}$ Jan, 2020. Further a correlation analysis was conducted with individual results of COVID-19 on one side and Sensex on other side.

For the purpose of study the secondary data has been used. The daily closing prices of Sensex has been collected from $12^{\text {th }}$ of March 2020 to $13^{\text {th }}$ January, 2021. Further the data of number of COVID cases confirmed, active cases, recovered cases and the number of death for the corresponding date had been collected. The data so collected had been tabulated and the correlation between the Sensex log return and the Covid-19 outcomes were 
calculated. The outcome of the finding is presented in tabular form and the same has been analysed to derive the conclusion from the collected data.

\section{Research}

The second week of Jan, 2020, has witnessed that the Pandemic was making its root in India and Sensex was swinging around the level of 40000. During the last two weeks of Feb,2020 people starting taking it on serious note and further in the month of March the lock down was declared in last week of this month. Till the mid of the Feb, 2020 it was observed that the market was range bond and was swinging close to 40k points. One of the remarkable point is quite ahead of Covid-19 spread the crude oil price has started falling in the international market and the price of West Texas Intermediate Crude oil price fell to negative 37.63 USD per barrel. On April 20 to April, 22 of 2020 the market has witnessed the lowest ever oil price. The two incidents happening together had also affected the global financial market and the Indian market was not an exception to it. Sensex had witnessed a fall of almost $15 \mathrm{~K}$ in just couple of weeks in the month of March,2020. It is interesting to know that the reason for this market crash was due to Covid -19 spread only or there was some more story behind this.

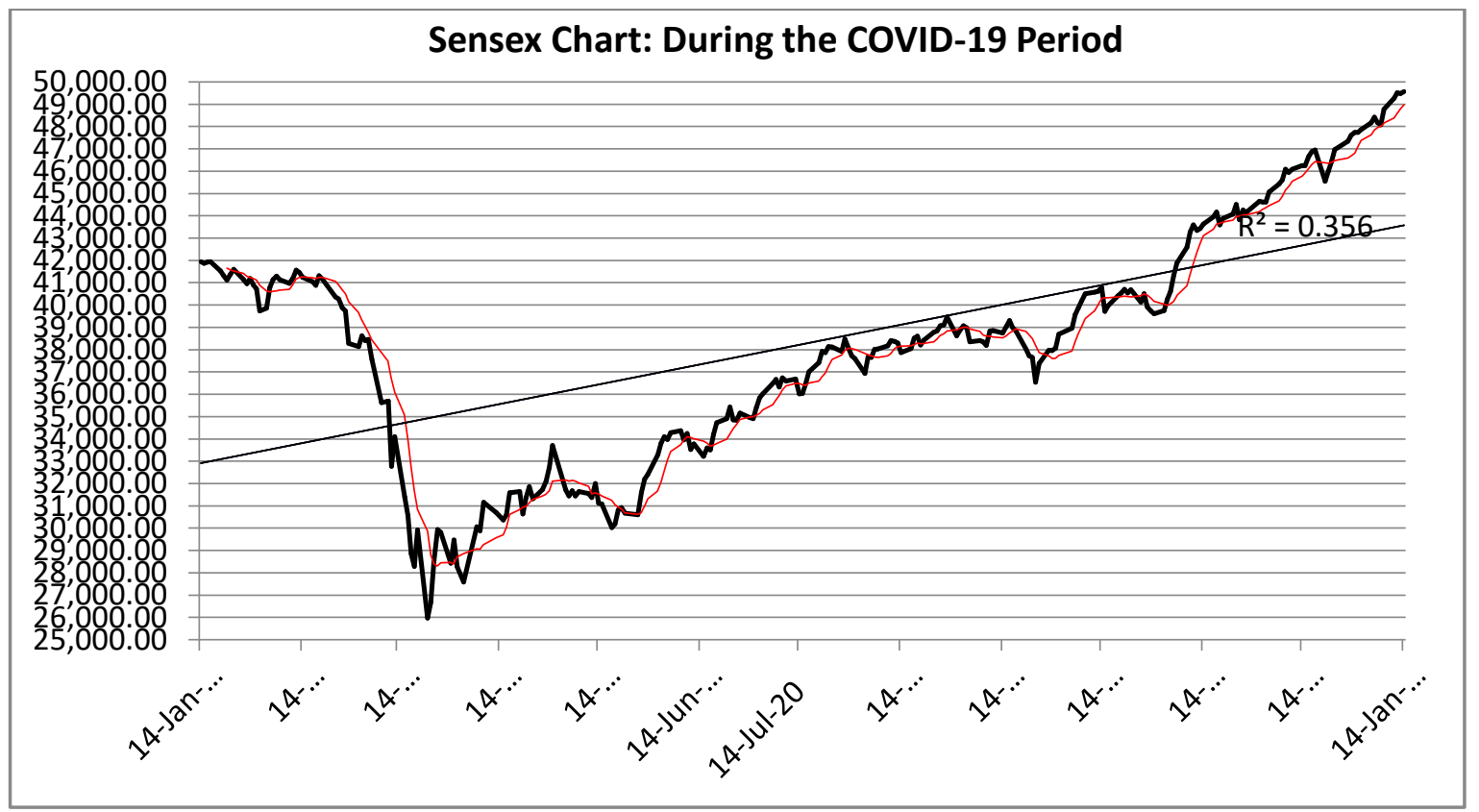

Major collapse signal started in the last week of Feb, 2020 when market started falling from $41 \mathrm{~K}$ and then it showed almost daily fall till the trend was broken. The following graph shows the journey of the market during the COVID-19 period. The black line shows the daily price and the red line is 7 days moving average. The $\mathrm{R}^{2}$ value of the Sensex with the linear trend line during this period was found to be 0.356 .

The number of COVID -19 cases, active cases and recovered cases till date is plotted in following chart.

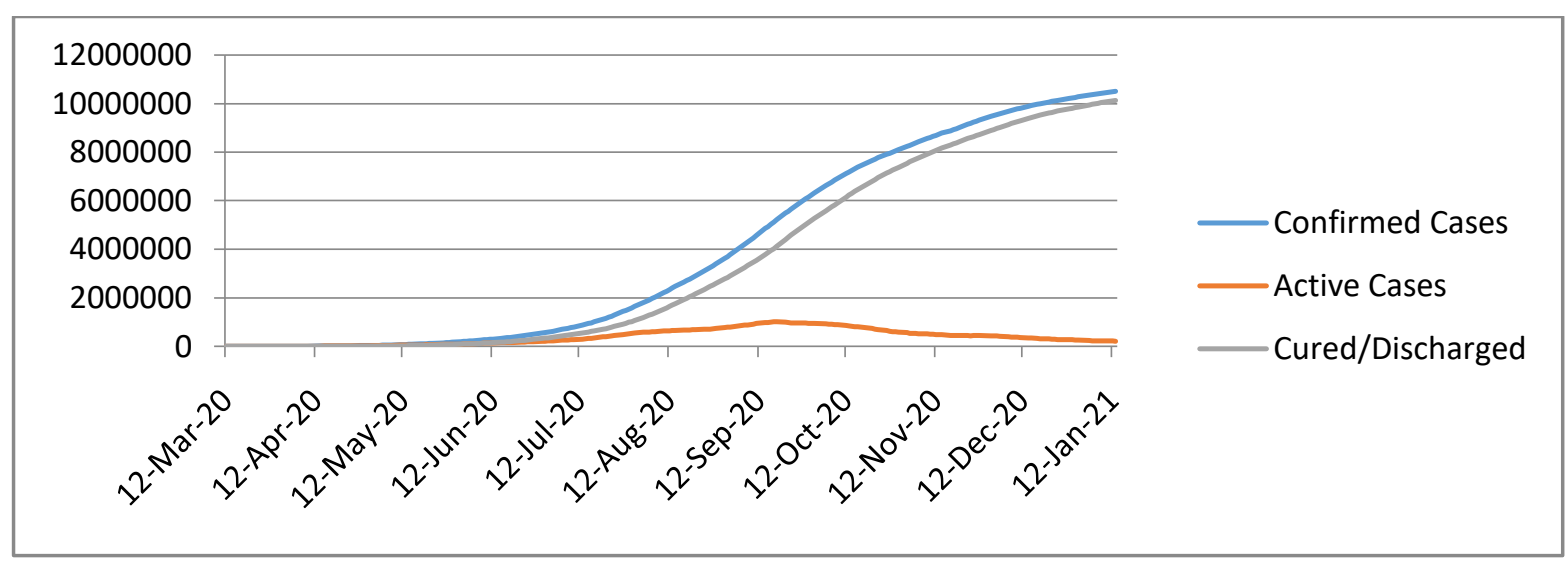

The relationship between the confirmed cased, active cased, cured / discharged cases, death and the price was tried to be found out. From the below table the price was found to be very much correlated with confirmed cased, cured cased and deaths whereas the correlation between the active cases and the price was found to be relatively very low. The finding seems to be very surprising as the active cases were more prone to spread the virus attack but the market has given more weight to other factors which means the information about the active cases were 
not much incorporated in the price of the Sensex during the span taken for the purpose of this research, which should have actually done. The finding shows that people have given more weight to death followed by discharged cases, confirmed cases and at last the cured/ discharged cases. One more facts can be derived from the data that people are more concerned about the result rather than the factors responsible for the result and hence the news headline during the initial days of the pandemic the confirmed cases and death has more impacted the market. However the active cases which was a major danger for the opening of the economic activity in the country has shown a relatively low correlation in spite of the fact that the active cases were the real threat for opening up the economic activity. More number of the active cases will obviously result in more spread of the virus in the population. If one will look into the correlation coefficient of cured to discharged cases to Price a high correlation of 0.91 was found which means the recovery news has more impacted the market as compared to the news of active cases. This means the people were more concerned about the final effect of the spread and as the assurance to lesser chance of death due to Covid -19 was confirmed the market started to behave in positive node and shown its recovery from the month of June,2020 and reached back to its initial $40 \mathrm{~K}$ mark on $3^{\text {rd }}$ Nov, 2020. In the light of this finding it would be an interesting to understand that the negative news of COVID-19 spread in Media in the initial days of spread may have affected the market in relatively more adverse manner as it would have been, if this would have been served otherwise.

Correlation table

\begin{tabular}{|l|l|l|l|l|l|}
\hline & Confirmed Cases & Active Cases & Cured/Discharged & Death & Sensex \\
\hline Confirmed Cases & 1 & & & & \\
\hline Active Cases & 0.471432186 & 1 & & & \\
\hline Cured/Discharged & 0.997101137 & 0.402966276 & 1 & & \\
\hline Death & 0.996665117 & 0.530426727 & 0.988521452 & 1 & \\
\hline Price & 0.918377518 & 0.467324096 & 0.912530838 & 0.932577 & 1 \\
\hline
\end{tabular}

Further the relationship between the log return of the Sensex and the related Covid-19 results were found to be surprising. The correlation coefficient the log return of Sensex was found to be marginally negatively correlated when compared to the number of confirmed cases and death cases on daily basis. Same was the case of per day death cases reported. However in the cases of cured/ discharge cases was found to be slight positive.

\begin{tabular}{|l|l|l|l|l|}
\hline & & & & \\
& Confirmed Cases & Cured/Discharged & Death & $\begin{array}{l}\text { log return } \\
\text { on Sensex }\end{array}$ \\
\hline Confirmed Cases & 1 & & & \\
\hline Cured/Discharged & 0.972171015 & 1 & & \\
\hline Death & 0.969524165 & 0.925002684 & 1 & \\
\hline log return & -0.007164548 & 0.005152737 & -0.00541 & 1 \\
\hline
\end{tabular}

\section{Conclusion:}

From the above analysis it can be concluded that during the approximately one year of post COVID -19 period the market was not much affected by the COVID-19 in the longer run although significant relation was found between the number of confirmed cases, cured/ discharged cases, deaths and log return of the Sensex on daily basis. However the level of correlation was found to be much higher in case of cumulative cases of confirmed cases, Cured/discharged cases, death and Sensex absolute value on daily basis. Whereas, relatively low correlation was found between the number of active cases and the Sensex log return on daliy basis. This means people were more vulnerable to media highlights as in the initial couple of months of the spread media has given more space to the news of number of confirmed cases and deaths as compared to the active cases. As the people started realizing that the fatality rate in India is much less than as it was projected the market started to move in the direction of recovery from the month of June onward and reached back to its initial level of $40 \mathrm{~K}$ mark. The lesser information about the virus and its after effect has led to a panic situation in the initial days, which led to sharp fall in the Sensex in the early days of the Pandemic. As the more matured news started coming in the market the recovery was visible. It would be very interesting to study of the role of media news related to pandemic for the fall in the market. 
Therefore based on the above analysis it can be concluded that the COVID-19 has not much impacted the financial market to very extent if considered on long term basis i.e. over a approx spam of one year of the detection of first Covid-19 case detected in India. Further the market was very much affected in shorter duration when at the initial level the COVID -19 cases was declared. But gradually over a period of time it has come to almost its level as it was in the month November and December of 2020. Hence it can be concluded from the study that Indian stock market has behaved in much matured manner as far as the outbreak of COVID-19 is concerned.

\section{References}

Baret S, Celner A, O’Reilly M, Shilling M, (2020) COVID-19 potential implications for the banking and capital market sector. Deloitte insights

Sansa A N, (2020) The impact of the COVID-19 on the financial markets: Evidence from China and USA. Electronic Research Journal of Social Science and Humanities. www.eresearchjournal.com So W, (2020) Corona virus impact on stock market South Korea 2020

Vishnoi A, Mookerjee I, (2020) Perfect Storm plunges Asia stocks Bear Markets one by one. Bloomberg.

Shehzad K, Xiaoxing L, Kazouz H, (2020) COVID-19's disaster are perilous than Global Financial Crisis: A rumor or Fact? Financial research Letters https://doi.org/10.1016/j.frl.2020.101669

Georgieva K, (2020) IMF Managing Director Kristalina Georgieva’s Statement Following a G20 Ministerial Call on the Coronavirus Emergency.

Rakshit B, Basistha D, (2020) Can India stay immune enough to combat COVID-19 pandemic? An economic query. Journal of public affairs. https://doi.org/10.

Sakthive P, Kumar K V, Raghuram G, Govindaranjan K, Anand V V, (2014) Impact of Global Financial Crisis on Stock Market Volatility: Evidence from India. Asian Social Science, 10(10)86-94.

Rakshit B, Basistha D, (2020) Can India stay immune enough to combat COVID-19 pandemic? An economic query. Journal of public affairs. https://doi.org/10. 